it may not be generally known that more than thirty years ago a skating pond was constructed in Liverpool, consisting, I believe, entirely of crystallised Glauber's salt. I have a perfect recollection of this miniature lake with its grotto-like surroundings, of its black looking ice with innumerable white scorings marking the tracks of the skaters, yet, strange to say, I cannot remember whether I skated on it myself. The impression that I did seems to be confused with other skating scenes. This perhaps does not look like very reliable evidence, but that the "rink" (under another name) of artificial ice did exist, and was popular, will no doubt be affirmed by many witnesses besides myself. The date would be about I 845 , if I am not mistaken, and the speculation ultimately failed owing to a public impression (possibly a wrong one) that the exhalations from the surface of the pond caused sickness and headache.

R. H.

\section{The Stone in the Swallow}

YouR correspondent, Dr. P. P. C. Hoek, requests information respecting the origin of the fable to which the poet Longfellow refers at the end of the first part of "Evangeline""The stone in the nest of the swallow." In Burton's "Anatomy of Melancholy," p. 434, at the top (Wm. Tegg's edition), after describing in the delightfully quaint style of the age the curative virtues of various stones, he quotes the following:-

"In the belly of a swallow there is a stone called "chelidonits,' which, if it be lapped in a fair cloth and tied to the right arm, will cure lunatics, madmen, make them amiable and merry."

In a foot-note there are references made to the following authors:-Albertus, Eucellius, cap. 44, lib. 3; Plin, lib. 37, cap. Io; Jacobus de Dondis, \&c.

It seems probable that Longfellow got his version of the story from some of the descendants of the French Acadians, to whom the poem relates, and it may have come down from the same sources from which Burton derives his account of the matter. It may be noted that the two versions do not in any way clash, Burton's simply referring to the whereabouts of the stone, "in the belly of the swallow," its name and benefits to those afficted with insanity; while Longfellow's version relates more to the finding and locality of the stone and its uses to the young swallows, leaving its supposed value to man, depending on the genera term of being "lucky."

Trinidad, West Indies, May 24

\section{Stags' Horns}

In reference to the opinions recently expressed in your journal regarding the disappearance of the horns of stags, deer, \&c., I may mention that this is usually attributed here to the action of rodents rather than of the deer themselves. Even if a deer should occasionally be seen gnawing a horn it would be very difficult to account for the disappearance of all the annual crop of antlers in this way. From the nature of their dentition (having no incisor teeth in the upper jaw) the destruction of such a mass of hard material must be very difficult. Moreover slight examination will show whether the tooth marks are those of the large teeth of a deer or of the small incisors of a rodent.

Antioch College, Ohio, U.S.A.

E. W. Claypole

\section{ON SOME POINTS CONNECTED WITH TERRESTRIAL MAGNETISM}

T HAVE on more than one previous occasion brcught forward some of the various points which are here grouped together. These points are three in number.

(a) Regarding the sustaining power of the earth's magnetism.

$(\beta)$ Regarding the diurnal and other changes of the same.

$(\gamma)$ Regarding earth currents and auroras.

I may state at once that this only professes to be a working hypothesis.

(a) Regarding the Sustaining Power of the Earth's Maynetism.-I do not here intend to discuss the cause of the earth's magnetism, but I would ask in the first place if it is not possible that this cause may be something small and one which (assuming it to continue at the present moment) we may not readily perceive. If we assume this cause or magnetic nucleus to be small is it not possible to imagine that there is a machinery which acts upon this nucleus (just as we have in certain magneto-electric engines) so as to swell up the magnetism of the earth ultimately to saturation. ${ }^{1}$

May not this machinery be the great convection currents, the anti-trades, that go from the equator to the poles in the upper regions of the earth's atmosphere, and which may be looked on as conductors moving across lines of magnetic force?

It would appear to me that the tendency of such currents will be to swell up and sustain the magnetism of the earth.

( $\beta$ ) Regarding the Diurnal and other Changes of Terrestrial Magnetism. - It will of course be natural, entertaining the views now enunciated, to regard the diurnal changes of the convection currents of the earth's atmosphere, as these are manifested in the upper regions, to be the cause of the diurnal changes of terrestrial magnetism.

If this view be taken it might be argued that wind changes in these upper regions should also produce magnetic variations. The reply is that apparently they do. In conjunction with Mr. Morisabro Hiraoka I have compared together the simultaneous records of magnetic declination ranges at $\mathrm{Kew}$ and at Trevandrum, and I find evidence of a progress of things from west to east, so that on the whole a particular magnetic-range phenomenon occurs at Kew 97 days before it occurs at Trevandrum. Again, I have attempted to show, in conjunction with Mr. Dodgson, that a particular magnetic phenomenon occurs at Kew one day before it occurs at Prague.

It would thus appear that there is a progress of magnetic phenomena from west to east, just as we know there is a progress of meteorological phenomena. As, however, the meteorological phenomena which we can examine occur in the lower atmospheric regions, while the magnetic phenomena are, according to this hypothesis, associated with currents in the higher regions, it does not follow that magnetic and meteorological phenomena should travel from west to east at the same rate. I may also mention that we have reason to believe that magnetic changes lag behind corresponding solar changes just as meteorological changes would do.

It is manifest that it will be comparatively easy to settle the fact of a progress from west to east of magnetic weather, and that if such exists it will most readily ally itself with the hypothesis above mentioned.

In the next place, if we regard those changes in the convection-currents of the earth which depend on the year we have reason to imagine that such are most pronounced at the equinoxes. It is also well known that magnetic disturbances are most frequent at these times.

Let us next proceed to regard the secular change of the earth's magnetism. To account for this magneticians have felt the need of something movable, and the hypothesis of a "little earth," a solid nucleus moving within the recesses of our planet, has found much support. But is it not more likely that the result may be caused by a secular variation in the distribution of the convectioncurrents of the earth? If the question be asked, What reason have we for imagining the existence of such a variation, the answer will be, $A$ much better reason than we have for entertaining the conception of a "little earth." For there is some reason, at any rate, for imagining the power of the sun to be subject to a complicated series of perindicities. Now a secular variation in the poiver of the sun would produce a secular change not only in the intensity, but in the direction of the convectioncurrents of the earth, and, according to the above hypo-

I If I am not mistaken Sir W. Thomson is inclined to regard the earth as a magneto-electric engine. 